\title{
INSTITUTO POLOIGUASSU: ATOR PARADIPLOMÁTICO DA REGIÃO TRINACIONAL DO IGUASSU
}

\author{
Alfredo Brito Aguiar ${ }^{1}$ \\ Andressa Szekut ${ }^{2}$ \\ Petterson Eduardo S Gherlandi ${ }^{3}$
}

\begin{abstract}
RESUMO: O Instituto Polo Internacional Iguassu é uma entidade do terceiro setor que desde 1996 atua de diferentes formas na Região Trinacional do Iguassu. O Poloiguassu, como é chamado, nasce a partir da mobilização de empresários dos três países em busca de integração das cidades fronteiriças para o desenvolvimento de forma conjunta. Reflexo do contexto vivido, o instituto objetiva atuar de diferentes formas para o desenvolvimento integrado do turismo na região fronteiriça, o que o aproxima da concepção de paradiplomacia. Assim, a pergunta que conduziu essa pesquisa foi: como se dá a atuação internacional do Poloiguassu? A partir dela objetiva-se levantar e analisar as atividades internacionais do Instituto Polo Iguassu a fim de problematizar teoria e prática da paradiplomacia por parte do instituto. Para a execução deste estudo utilizamos uma abordagem qualitativa cruzando métodos da história oral e do levantamento documental direto e indireto a respeito do histórico de atuação do instituto. Com isso, identificou-se que suas atuações internacionais ao longo dos anos permitem visualizar a complexidade das relações interinstitucionais fronteiriças e notase nesse contexto o potencial articulador do instituto. Sendo que, nos primeiros anos teve uma atuação mais de projeção externa e nos últimos anos mais de mediação (a partir da experiência técnica, de captação de recursos e etc), sempre internacional e voltada para o turismo, o que se entende diretamente relacionado ao que se concebe como paradiplomacia.
\end{abstract}

Palavras-chave: Paradiplomacia; PoloIguassu; trinacional.

\section{INSTITUTE POLO IGUASSU: PARADIPLOMATIC ACTOR IN THE IGUASSU TRINATIONAL REGION}

\begin{abstract}
The Institute Polo Internacional Iguassu is a third sector entity that since 1996 has been operating in different ways in the Iguassu Trinational Region. Poloiguassu, as it is called, is born from the mobilization of entrepreneurs from the

\footnotetext{
${ }^{1}$ Bacharel em Turismo pela Universidade Estadual do Oeste do Paraná - UNIOESTE. Assistente de Projetos do setor de Gestão de Pesquisas e Inovação do Instituto Polo Internacional Iguassu. E-mail: alfredobaguiar@hotmail.com

${ }^{2}$ Bolsista de pós-doutorado CAPES no programa de pós-graduação em Sociedade Cultura e Fronteiras UNIOESTE. Docente do curso de Turismo - UNIOESTE. Doutora em Memória Social e Patrimônio Cultural - UFPEL, Mestre em Sociedade, Cultura e Fronteiras; Especialista em Gestão e Projetos em Turismo; e Bacharel em Turismo. E-mail: andressaszekut@ gmail.com

${ }^{3}$ Mestrando em Relações Internacionais - Programa de Pós-Graduação de Relações Internacionais da Universidade Federal da Integração Latino-Americana - UNILA. Assistente de Projetos do setor de Gestão de Pesquisas e Inovação do Instituto Polo Internacional Iguassu. E-mail: gherlandi@gmail.com
} 
three countries in search of integration of border cities for joint development. Reflecting the context experienced, the institute aims to act in different ways for the integrated development of tourism in the border region, which brings it closer to the concept of paradiplomacy. Thus, the question that led this research was: how does Poloiguassu's international performance take place? Based on it, the objective is to survey and analyze the international activities of the Institute Polo Iguassu to problematize theory and practice of paradiplomacy by the institute. For the execution of this study, we used a qualitative approach crossing methods of oral history and direct and indirect documentary survey regarding the history of the institute. With that, it was identified that its international actions over the years allow to visualize the complexity of border interinstitutional relations and in this context, it is noted the potential articulator of the institute. Being that, in the first years it had more of an external projection and in the last years more of mediation (based on technical experience, fundraising and etc.), always international and focused on tourism, which is understood directly related to what is conceived as paradiplomacy.

Keywords: Paradiplomacy; PoloIguassu; trinational.

\section{INTRODUÇÃO}

Este estudo parte da experiência de atuação do Instituto Polo Internacional Iguassu (Poloiguassu) na Região Trinacional do Iguassu, entre Brasil, Paraguai e Argentina. Entidade do $3^{\circ}$ setor que surge em 1996 por meio da articulação de lideranças do setor turístico da região, o Poloiguassu tem uma trajetória de atuação internacional que remete a sua inicial constituição composta por presidentes advindos dos três países que compõem a região. Identificando suas principais atuações para esta localidade, acreditamos que o instituto possa ser considerado um ator paradiplomático por atuar como mediador e articulador dos interesses coletivos da região, bem como por defendê-los em espaços externos à localidade.

Esse interesse de pesquisa surge de nossa experiência cotidiana que revela que, embora não faltem iniciativas e espaços de interação internacional na região, falta sistematização de informações sobre esses espaços, bem como sobre quem os compõe, como se dão, quais suas agendas, objetivos e resultados. Pensando nisso, nos propusemos a identificar esses aspectos partindo inicialmente de um dos atores internacionais da região, o Poloiguassu.

A escolha deveu-se ao fato de os autores deste estudo fazerem parte da instituição como colaboradores ou prestadores de serviço. Além do que, atuando na região desde 1996, o instituto completará vinte e cinco (25) anos em 2021 e, apesar de 
contar com amplo arquivo, ainda não possuía um levantamento sistemático e contextualizado de suas ações, possuindo apenas um mini-currículo institucional.

Partindo desse recorte, a pergunta que passou a conduzir nossa pesquisa foi: como se dá a atuação internacional do Poloiguassu? A partir dela delimitamos nosso objetivo como sendo: levantar e analisar as atividades internacionais do Instituto Polo Iguassu a fim de problematizar teoria e prática da paradiplomacia por parte do instituto. O conceito de paradiplomacia aparece aqui devido a capacidade que tal concepção tem em descrever determinadas atividades características da Região Trinacional do Iguassu, principalmente no que diz respeito às relações internacionais e a projeção internacional da região, bem como sobre a participação de atores não-estatais nesse processo.

Dito isso, para a execução deste estudo utilizamos uma abordagem qualitativa cruzando métodos da história oral e do levantamento documental direto e indireto a respeito do histórico de atuação do instituto. Fizemos essa opção visando preencher lacunas ora não registradas na documentação, ora não acessadas pela memória da entrevistada.

Para o levantamento bibliográfico, inicialmente foi feita uma pesquisa com a palavras "Poloiguassu"; "Polo Iguassu" e "Polo Internacional Iguassu" na plataforma Google Acadêmico. Esgotadas as fontes desse buscador, realizou-se a mesma pesquisa nos repositórios institucionais da Universidade Federal da Integração Latino-americana (UNILA) e da Universidade Estadual do Paraná (UNIOESTE). Posteriormente ainda serviram como fonte de busca dos mesmos termos os anais dos Festivais Internacionais de Turismo (FIT - Festival das Cataratas). Ao longo da pesquisa, após realização da entrevista, também foram feitas buscas no Google relativas aos projetos e pessoas mencionadas pela entrevistada.

Quanto ao levantamento documental, a principal fonte de informações foi o site do instituto (poloiguassu.org), bem como o servidor online e o arquivo físico da instituição. Tanto o servidor quanto o arquivo são privados, porém como os autores do estudo são também funcionários da instituição tiveram acesso autorizado para a pesquisa. O método de coleta das informações foi causalístico: realizou-se um levantamento geral dos projetos executados ao longo dos anos a partir de um documento de referência chamado "mini-currículo institucional" e da seção "nossa história" no site do instituto. Nesse sentido, a pesquisa no servidor e nos arquivos físicos serviram para 
verificação de possíveis projetos ou iniciativas que pudessem não ter sido informadas nos documentos de referência, bem como para certificação das informações constantes naqueles arquivos e na entrevista.

Por fim, quanto à entrevista realizada, a escolha da entrevistada se deu pela facilidade de contato com a mesma e pela identificação dela como uma primeira ponta para a rede de contatos que se pretende entrevistar a fim de, posteriormente, aprofundar a pesquisa. Além disso, à frente da instituição há 10 anos (primeiramente como presidente e atualmente como coordenadora geral) e colaboradora do instituto há 14 anos, a escolhida é a pessoa que esteve há mais tempo atuando na entidade. Sabíamos dessa informação por conhecê-la pessoalmente e por conta dos registros arquivados. Dessa forma, apesar da vontade em entrevistar outros atores, como os sócios-fundadores do instituto e outros associados, acreditamos que ela seria a melhor opção diante do tempo para execução do estudo.

Quanto a análise dos resultados, buscamos realizar uma descrição qualitativa dos projetos levantados, identificando a área de inserção do projeto, principais atores envolvidos e contexto de execução. Dessa forma, pudemos compor o cenário de atuação do Poloiguassu identificando parte de sua rede de trabalho, seus principais temas de interesse, e qual papel assumiu em cada ação (gestão técnica, articulação políticainstitucional, ambos etc.).

\section{PARADIPLOMACIA NA TEORIA}

Também referida como Diplomacia Descentralizada (Keating, 2001), Pósdiplomacia (Aguirre, 1999) ou Diplomacia Multinível (Hocking, 1993 apud. Aguirre, 1999), a paradiplomacia é um conceito em discussão que ganha cada vez mais espaço na academia das relações internacionais. Suas origens remetem a década de 1980 no contexto de ampliação da participação de entes federados no cenário internacional. Naquele primeiro momento, o conceito serviu para abordar a projeção de regiões transfronteiriças que se articularam a partir dos governos não-centrais (GNCs) locais para lançarem-se no plano internacional (Aguirre, 1999).

Foram Duchacek e Soldatos (apud. Aguirre, 1999) os primeiros a se preocuparem com as interações desses novos atores com seus respectivos governos 
centrais, até então detentores exclusivos das atividades diplomáticas. Nesse cenário, o conceito de paradiplomacia se definiria pelo contato direto de GNCs com seus referentes nas mais diversas áreas a fim de estabelecer acordos mútuos, sem necessariamente passar pelo crivo dos governos centrais.

A partir dessa visão, observa-se que a paradiplomacia surge fortemente atrelada às intenções de cooperativismo transfronteiriço, configurada por interações locais (entre as localidades fronteiriças) e projeção conjunta da região para o exterior. A partir dessas primeiras definições, procurando compreender o que essa nova forma de inserção internacional representaria (para além de suas articulações com os governos centrais) Der Derian (apud. Aguirre, 2001) é outro autor que contribui para a definição do termo.

Para o autor (apud. Aguirre, 2001) a paradiplomacia poderia significar "qualquer tipo de atividade internacional não governamental [incluindo] de atores não-estatais [...] que poderiam ser [...] rotulados de 'diplomáticos' porque realmente operam, [...], uma 'mediação' entre realidades mutuamente 'estranhas' ou 'alienadas'". (AGUIRRE, 1999, p.196-197). Segundo essa lógica, por ser uma atividade diretamente relacionada com a diplomacia, a paradiplomacia representaria, tal qual sua antecessora, sobretudo um processo de mediação.

Ocorre que a Diplomacia estatal surge com o advento da modernidade europeia no contexto de formação dos primeiros Estados-nação, e se perpetua como uma tradição mantida até hoje. Todos os Estados possuem seus representantes diplomáticos, normalmente vinculados ao governo central. No Brasil, por exemplo, a diplomacia está vinculada a um ministério, que como sabemos está diretamente vinculado à Presidência da República.

Porém, o processo de globalização a partir da década de 1980 impõe novas lógicas às relações internacionais. Dentre elas, as cidades e regiões passam a ganhar muito mais peso no plano internacioanl. E, sendo assim, continuar atribuindo exclusivamente ao governo central o poder de realizar mediações com realidades distintas passa a fazer menos sentido.

Dessa forma, quando Der Derian (apud. Aguirre, 2001) diz que qualquer atividade internacional que opere mediações entre realidades distintas seria paradiplomacia, é porque para o autor, verificando a etimologia do conceito diplomacia e sua trajetória até tornar-se paradiplomacia, não faria sentido seguir restringindo esse 
processo as estruturas formais do Estado. A esse respeito, o autor completa: "[a paradiplomacia] é uma 'diplomacia' politicamente 'excêntrica', democraticamente não controlada, privada ou corporativa, religiosa ou mediática, estritamente não governamental" (AGUIRRE, 1999, p. 195).

Como se pode observar, nessa perspectiva, a centralidade do conceito não está no ator, mas sim no ato de se promover mediações. Contudo, tal interpretação incorre na possibilidade de se compreender qualquer tipo de negociação internacional como uma atividade paradiplomática, o que seria problemático, afinal, quando duas multinacionais estão mediando interesses para o desenvolvimento de um produto, isso também seria paradiplomacia? Certamente não.

Nesse caso, é a definição de Noé Conargo (1999), com toques críticos de Michael Keating (2001), que nos ajuda a melhor conceitualizar a paradiplomacia. Segundo Conargo:

\begin{abstract}
A paradiplomacia pode ser definida como o envolvimento de governos não centrais nas relações internacionais por meio do estabelecimento de contatos permanentes ou ad hoc com entidades estrangeiras, públicos ou privados, com o objetivo de promover questões socioeconômicas ou culturais, bem como qualquer outra dimensão estrangeira das suas competências constitucionais. (CONARGO, 1999 In KEATING; ALDECOA, 1999, tradução nossa).
\end{abstract}

Fica evidente que para o autor, diferentemente do que para Der Derian, é importante sim definir o agente paradiplomático. Em sua visão essa posição seria ocupada pelos GNCs. Além disso, também entram na definição: os meios pelos quais se exerce a paradiplomacia, bem como as contrapartes e os objetivos. Nota-se que, também se diferenciando de Duchacek e Soldatos, Conargo identifica possibilidade de interação com atores diversos, não apenas GNCs. Ainda assim, a presença de ao menos um GNC na interação seria indispensável para caracterizar a paradiplomacia como tal. Por fim, verifica-se que os objetivos são amplos e precisam apenas respeitar as competências constitucionais dos GNCs.

O problema dessa definição, em nossa opinião, é que, ao definir os GNCs como os agentes a priori da paradiplomacia, ela pode desconsiderar os demais atores que compõem o governo de determinada localidade, tais como a sociedade civil, o setor privado e o terceiro setor, podendo dar a entender que o exercício da paradiplomacia 
seria exclusividade da administração pública. Assim, para evitar maiores transformações no que tange o conceito, concordamos com Keating (2001) ao dizer que é preciso compreender o governo como algo que vai além das estruturas do Estado.

$\mathrm{O}$ autor entende, desse modo, que conceitos como o de governança não deveriam ter um espaço distinto, já que a concepção de governo em si deve abarcar os demais setores nas tomadas de decisão. Complementando essa argumentação Keating e Aldecoa (1999, p. 9, tradução nossa) continuam: “A paradiplomacia [...] se caracteriza por um alto grau de envolvimento da sociedade civil e do setor privado. Isso varia de acordo com fatores políticos e institucionais".

Nesses termos, acrescentamos ainda uma perspectiva própria com base nessas leituras de que, mais do que entender o governo local como um conjunto de atores, a partir da realidade que nos cerca na Região Trinacional do Iguassu, é necessário compreender que diferentes entidades da sociedade civil atuam de forma diplomática quando representam interesses públicos ou coletivos da localidade em âmbito internacional. Para corroborar essa perspectiva acreditamos que a contribuição teórica de Brian Hocking (1993 apud. AGUIRRE, 1999) ajuda a incorporar essa perspectiva.

Para esse autor, diferentemente dos anteriores, a própria concepção de paradiplomacia não se faz necessária já que, para ele, o conceito representaria nada mais que uma "domesticação" de um fenômeno tradicionalmente vinculado à política internacional (dos Estados). A partir dessa percepção o autor argumenta que os GNCs, diferentemente dos governos centrais:

[...] estão localizados em um meio diplomático complexo que não reconhece os territórios exclusivos do doméstico e do internacional, mas combina os dois de várias maneiras a pedido de uma gama de forças localizadas em diferentes níveis políticos. Aqui, a diplomacia internacional não é considerada um processo segmentado presidido por guardiões indiscutíveis, mas como uma teia de interações com um elenco variável de jogadores que irão interagir de maneiras diferentes dependendo da questão, de seus interesses e da capacidade de atuar em um ambiente político multinível. (HOCKING, 1993, p. 36 apud AGUIRRE, 1999, p. 200, tradução nossa).

Nessa perspectiva, a paradiplomacia é apresentada de forma menos simplista revelando seu potencial de atuação não apenas em diferentes temas, mas em diferentes esferas e hierarquias de interação. Essa visão é cara para o intuito deste estudo pois 
destaca a complexidade da atuação paradiplomática bem como sua multiplicidade de aplicação. Além do que, segundo Aguirre (1999) Hockign, ao conceitualizar essa diplomacia multinível, define que os GNCs são na verdade "atores totalmente internacionais, tão complexos e plurais quanto o Estado a que pertencem." (AGUIRRE, 1999, p. 201, tradução nossa). Sendo assim, o autor contribui para uma visão de que, diante dessa completa capacidade de atuar internacionalmente de forma até mais complexa que os governos centrais, a atuação dos GNCs será sempre heterogênea e condizente com o contexto no qual está inserido (HOCKING apud. AGUIRRE, 1999).

Nessa medida, a partir de uma interpretação combinada entre as diferentes abordagens elencadas até aqui e atentos a realidade a qual se aplica esse estudo, a Região Trinacional do Iguaçu, a interpretação de paradiplomacia utilizada neste artigo é: o envolvimento de entidades - sejam elas públicas, privadas, da sociedade civil ou do terceiro setor -, comprometidas com o interesse público de uma localidade ou região, com atores de jurisdições distintas da sua (provenientes de outro Estado ou economia) ou organizações internacionais, com o objetivo de promover questões diversas de forma a mediar realidades distintas convergentes ou não. Tais mediações podem se dar entre localidades, ou seja, entre as entidades de uma localidade e outra, ou entre localidades e OI's, bem como entre localidades e o governo central de determinados países.

Tendo apresentado tal definição partimos para a apresentação de nosso objeto de estudo: o Instituto Polo Internacional Iguassu. Na próxima seção apresentamos o histórico de atuação da instituição para servir de base para análise final a respeito de como se dá a atuação internacional do instituto.

\section{POLOIGUASSU, O INSTITUTO E SUA ATUAÇÃO}

O Instituto Polo Internacional Iguassu (Poloiguassu), de acordo com sua Ata de constituição, foi criado em 09 de julho de 1996, por meio da Comissão de Integração ao Polo Internacional Iguaçu, constituída com a finalidade específica de elaborar o estatuto para a criação da entidade. É importante salientar que o comerciante Névio Morello Rafagnin começou a mobilizar empresários dos três países e formar grupos de trabalho em 1995. Dessa forma, com a primeira assembleia, Sr. Névio foi intitulado como presidente do instituto com três Vice-presidentes, sendo eles, Gustavo Arralba, 
representando a Argentina, Faisal Saleh, representando o Brasil e Ramón Alderete, representando o Paraguai. Além disso, foram criadas bases de atuação nos três países, com indicação de responsável para cada base e um Conselho Diretor Trinacional também com representantes de cada país. Este documento, redigido em português e espanhol, institucionaliza uma mobilização entre empresários locais dos três países.

Conforme atas das primeiras reuniões promovidas ainda em 1995, o grupo se mobilizou em torno da necessidade de melhorar a imagem da região fronteiriça, e para isso propuseram a contratação de uma agência para a realização de uma pesquisa de opinião, com fim de ter um diagnóstico sobre as cidades fronteiriças dos três países, e posteriormente desenvolver um planejamento de forma integrada e agir em conjunto para a formação de uma imagem positiva para o Polo Internacional Iguassu. Esta mobilização entre empresários foi impulsionada pela crise sofrida pelo setor na região em meados da década de 1990. "Ao final dos anos 1990, [...] em função da crise econômica no Brasil e da crise política e econômica iniciada na Argentina, abriu-se espaço para a edição de algumas decisões mais voltadas para o campo político na integração regional." (PENHA; DESIDERÁ NETO, 2017, p.204).

Nesse contexto, também se tem, em 1991, a fundação do Mercado Comum do Sul (MERCOSUL), entre Brasil, Argentina, Paraguai e Uruguai, signatários do Tratado de Assunção. Esta iniciativa de integração regional da América Latina, surgiu no contexto da redemocratização e reaproximação dos países da região ao final da década de 80. O Tratado de Assunção, instrumento fundacional do MERCOSUL, estabeleceu um modelo de integração profunda, com os objetivos centrais de conformação de um mercado comum - com livre circulação interna de bens, serviços e fatores produtivos - o estabelecimento de uma Tarifa Externa Comum (TEC) no comércio com terceiros países e a adoção de uma política comercial comum (MERCOSUL. s.d).

Dessa forma, o mercado do turismo estava em baixa, existia a percepção de interdependência do setor entre as cidades e o cenário apresentava-se favorável para iniciativas de integração, principalmente comercial. Com isso, desde a primeira reunião de articulação entre os empresários locais menciona-se a aproximação ao MERCOSUL para benefício da região. Por ser uma zona de fronteira de três países membros do MERCOSUL, as cidades representavam um núcleo logístico importante. "Historicamente à criação do MERCOSUL o turismo está na pauta, focalizando a 
fronteira trinacional como localidade de destinos turísticos de grande destaque no cenário nacional e internacional” (BIANCHIN, 2018, p 13). E em 1997, o bloco reconheceu a atividade turística na região ao criar o recorte: Pólo Turístico Internacional Iguassu, através da Resolução MERCOSUL/GMC. 41/97.

A criação do Polo Turístico está diretamente relacionada com as iniciativas do Poloiguassu, que com a articulação entre os empresários e entidades, oficializaram a criação do instituto e investiram na realização da pesquisa, que deu origem ao $1^{\circ}$ Diagnóstico Turístico de infraestrutura industrial, comercial e de serviços da Região Trinacional do Iguassu (1996). Esta formalização do interesse turístico da região compunha as estratégias de mudança de imagem do destino, que entendia-se que era negativa.

A pesquisa sobre o instituto e sua atuação na região ainda está em andamento, então os seus documentos estão em fase de catalogação e fichamento. Contudo, já foi possível identificar que a atuação inicial do instituto foi fortemente política, atuando como articulador para a integração regional e visualizando um "lobby" para fortalecer a imagem da região junto a entidades públicas e privadas. Aspecto que está registrado nos arquivos da instituição e é retratado pela fala de Fernanda Helena Fedrigo quando aborda a atuação político e institucional do Poloiguassu nos seus primeiros anos e complementa sobre as atividades da época:

[...] participar das reuniões especializadas do Mercosul e lutar dentro do Mercosul pra melhorar nossa condição de fronteira. Então, isso que regeu o Polo nos seus primeiros anos de vida, foi a essência do, do porquê que o Polo nasceu. Foi pra isso, melhorar nossas condições aqui na fronteira, de trânsito fronteiriço, de relacionamento e tudo mais. Mas como o Mercosul, né, não é, não existiu, não se consolidou, é, poucas coisas aconteceram. (FEDRIGO, informação verbal, 2020).

Fernanda, como já mencionamos, não fez parte deste momento da instituição. Para aprofundar essas questões o projeto ainda prevê entrevista com os diretores da época. Contudo, mesmo assim, já é possível ter uma referência de como atuava o instituto nos seus primeiros anos. E retrata-se dessa forma, como suas iniciativas políticas estavam diretamente relacionadas com o MERCOSUL, e com a não consolidação das ações propostas pelo Bloco, o próprio instituto alcança parcialmente seus objetivos iniciais. 
Isso pode ser observado pela transformação de atuação percebida tanto nos documentos administrativos como também nos projetos desenvolvidos pelo instituto. Levantou-se até o momento 6 estatutos do Poloiguassu de 2005 até 2019. Nesses documentos é possível identificar as transformações passadas pelo instituto, sendo elas principalmente, de estrutura de funcionamentos, pois a ideia inicial era ter representação nos três países, o que com o tempo foi dissolvido, restando apenas a base de atuação no Brasil; e de forma de atuação, sendo que seus primeiros objetivos posicionava o instituto como uma instituição articuladora e que passou a ser articuladora e executora, ampliando suas perspectivas com a adesão dos conceitos de Desenvolvimento Sustentável e Região Trinacional do Iguassu.

No estatuto de 2005, destaca-se que o Poloiguassu, tinha base operacional no Brasil (Foz do Iguaçu) e bases institucionais na Argentina (Puerto Iguazu) e no Paraguai (Ciudad del Este), e caracterizava-se como entidade trinacional, obedecendo às legislações das respectivas localidades de atuação. No artigo primeiro deste Estatuto consta que o Poloiguassu foi:

[...] Criado para apoiar as iniciativas, instituições e movimentos - e a executar ações - orientadas para a integração, estruturação e desenvolvimento: a) regional; b) departamental, estadual e provincial; c) do Mercosul e d) da ALCA; atuará nas áreas científico-tecnológica, cultural, ecológica e do meio ambiente, educacional, esportiva, de desenvolvimento institucional e socioeconômica, sendo regido pelo presente estatuto e pela legislação específica de cada país onde atue. (POLOIGUASSU, 2005).

O que permite perceber que buscava atuar em escala internacional e diretamente relacionada com os Blocos de Integração Regional. A partir das atividades propostas no estatuto, percebe-se que a busca de status de entidade trinacional do Mercosul segue até o estatuto de 2012, quando se tem a principal mudança de objetivo e atuação propostos, e que se segue com poucas alterações até 2019. A partir da entrevista com a Sra. Fernanda (informação verbal, 2020), levantou-se que, por falta de resultado nas articulações com o Mercosul, o instituto transformou sua atuação. Com isso, desde então o Estatuto trabalha então com o seguinte objetivo ${ }^{4}$ :

\footnotetext{
${ }^{4}$ Texto pouco alterado do Estatuto de 2012 e com nenhuma alteração para o Estatuto de 2019. 
Artigo $4^{\circ}$ - O POLOIGUASSU tem como objetivo atuar por meio de ações integradoras nas áreas de gestão, educação e pesquisa em turismo, contribuindo para o desenvolvimento sustentável do setor, em âmbito nacional e internacional, especialmente na Região Trinacional do Iguassu. (POLOIGUASSU, 2014).

Desde 2012 mantém-se a mesma essência dos primeiros anos do instituto, de apoio e promoção de atividades para o desenvolvimento do turismo na região, articulação interinstitucional internacional, apoio a iniciativas, estímulo a integração, fomento ao desenvolvimento. Mas não se tem mais registro de bases operacionais nos três países e são ampliadas as previsões de atuação social, com projetos culturais, educacionais, com jovens e adolescentes, e promoção de estudos, pesquisas (alguns já incluídos no Estatuto em 2008).

Percebe-se a mudança gradual e contínua da instituição em seus documentos. Dessa forma, pode-se dizer que o Poloiguassu atuou por alguns anos com projetos políticos e institucionais internacionais. As necessidades da região estavam no foco da atuação. Por exemplo, em 1999 realizou o Fórum Comunitário com a implantação do IQVI - Indicadores de Qualidade de Vida do Iguassu, para medição de índice do desenvolvimento humano com posterior encaminhamento às instituições Públicas e Privadas, de recomendações para tratamento e acompanhamento de questões essenciais da comunidade.

Nesse mesmo contexto, em 2001, concebeu o GUIA IGUASSU - Um Destino Turístico Para o Mundo - diagnóstico técnico e científico sobre a região; sugeriu para a região a palavra Trinacional, que apresenta uma região integrada e de desenvolvimento conjunto e harmônico, substituindo Tríplice Fronteira, cujo conceito reforça a ideia de separação e conflito; participou do Comitê Gestor que definiu o modelo do PTI - Parque Tecnológico Itaipu, com o qual firmou parceria para o desenvolvimento conjunto de ações, programas e projetos de interesse e objetivos comuns, focado na Integração Trinacional. Atuações que reforçam sua missão de desenvolvimento regional integrado, e o coloca cada vez mais como instituição parceira para articulação e execução de projetos que visam o benefício da região.

Nesse cenário o Poloiguassu se reestrutura e passa a executar cada vez mais ações técnicas, além das políticas inicialmente idealizadas. Como pode ser exemplificado com a execução em 2003 por parte do instituto do projeto Eirete Eirui - 
Educação para o Turismo na Região Trinacional, com crianças de 45 escolas públicas, mobilizando 250 educadores e 17 mil alunos do Brasil e Paraguai e Argentina. Este projeto, executado em conjunto com o PTI, e apoio de Itaipu Binacional e outras instituições, mostra a mudança de atuação e ação técnica pelo instituto.

Nesse mesmo sentido, a partir de 2006 o instituto começa a realizar o Projeto Trilha Jovem Iguassu - Turismo e Inclusão Social. O projeto tem como objetivo fomentar oportunidades de trabalho no setor de turismo e áreas afins para jovens que estejam em situação de risco e vulnerabilidade social. Fernanda (informação verbal, 2020), que entrou no Poloiguassu em 2006 para ser educadora base deste projeto, indicou em sua entrevista que ao longo dos anos houveram algumas tentativas de levar o projeto também para a Argentina e o Paraguai, mas que não houve êxito. Dessa forma, este é o primeiro grande projeto executado apenas no Brasil pelo instituto.

A partir do ano de 2012 o Poloiguassu começou a executar, em Foz do Iguaçu, o Programa Integrado de Educação Turística (PIET), com objetivo de promover o processo de educação e inclusão da comunidade na atividade turística. Por meio de oficinas, campanhas publicitárias, produção de material didático, entre outras atividades, mostra o turismo como força da economia e do desenvolvimento da cidade, a importância da hospitalidade e do bem receber aos turistas e buscar fortalecer em aluno e cidadão, o sentimento de pertencimento a cidade.

No que tange o desenvolvimento acadêmico, científico e para entender as dinâmicas da região trinacional, a partir de 2007 realizou, em parceria Fundação Parque Tecnológico Itaipu, três edições do Fórum Internacional de Turismo, com objetivo de promover a produção científica e o debate entre acadêmicos e empresários do turismo, reunindo mais de 1700 profissionais e pesquisadores. No ano de 2008 realizou o projeto Diálogos de Fronteira: Ciclo de Debates e Palestras, em que coordenou 40 eventos e mobilizou 10.000 estudiosos, pesquisadores, empresários e pessoas da sociedade civil.

Demonstrando reconhecimento nacional, em 2009, tornou-se conveniado com o Ministério do Turismo para a qualificação de profissionais do setor turístico de Foz do Iguaçu. O convênio, com o objetivo de melhorar a prestação de serviços voltados à cultura da hospitalidade, qualificou 94 profissionais e elaborou 235 planos de atividades a serem desenvolvidas no destino. Em 2010, firmou outro convênio com o Ministério do 
Turismo, para a execução do Projeto de Fortalecimento do Turismo Sustentável e de Base Comunitária, voltado a pequenos produtores rurais e artesãos.

A nível internacional, em 2010, o Poloiguassu foi efetivado como Membro Afiliado da Organização Mundial do Turismo (OMT), esse departamento da OMT reúne empresas e instituições pesquisadoras e educacionais a fim de engajar o diálogo e a troca de informações para a tomada de decisão e promoção do desenvolvimento sustentável do turismo com abrangência mundial (OMT, s/d). Ainda em 2010, o Instituto organizou e coordenou a $1^{\text {a }}$ reunião dos Membros Afiliados LatinoAmericanos da OMT, em que reuniu 10 países para debater sobre temas relevantes no desenvolvimento do turismo na América Latina. Estreitando ainda mais sua relação com a Organização Mundial do Turismo, em 2012 integrou a vice-presidência da organização, compondo a Junta Diretiva - órgão de assessoramento da Secretaria Geral da OMT. Tendo como principal função definir o programa geral de trabalho da OMT junto com outras entidades representantes (MINISTÉRIO DO TURISMO, 2012).

Em 2011, o Poloiguassu implantou o Núcleo de Elaboração de Projetos e Captação de Recursos para o Turismo no Destino Iguaçu em parceria com o Fundo de Promoção e Desenvolvimento Turístico do Iguaçu. Em 2013 implantou o Núcleo Integrado de Gerenciamento de Projetos (PROFOZ), dando continuidade ao trabalho do Núcleo que havia sido criado em 2011, trabalhado fortemente com a Secretaria Municipal de Turismo e pautado pelos projetos prioritários da Gestão Integrada do Turismo de Foz do Iguaçu. Esse, então, recebeu o Prêmio de "Boas Práticas em Turismo" pelo Ministério do Turismo e Sebrae, considerado uma ferramenta de grande importância para o desenvolvimento turístico de Foz do Iguaçu e região.

Estas são algumas das principais atuações do instituto, as quais utilizamos para exemplificar a transformação e extensão das ações desenvolvidas. Contudo, ressalta-se que estas são ações documentadas por meio de convênios, parcerias, contratos, prêmios, entre outros. Diante disso, percebe-se por meio da entrevista e também dos documentos levantados, que essas ações são envoltas por uma série de iniciativas e ações paralelas, que não necessariamente são formalizadas, mas que fomentam constantemente o trabalho em prol do desenvolvimento de forma integrada na região.

Por exemplo, em 2013 o Poloiguassu foi parceiro da Secretaria Municipal de Turismo de Foz do Iguaçu na construção do projeto para constituição do Observatório 
de Turismo de Foz do Iguaçu, que foi inserido na Política Municipal de Turismo com aprovação no dia 21 de Outubro de 2014 pelo Projeto de Lei 85/2014, na Seção IV e Art 13 e 14. Como desdobramento, nos anos seguintes foram realizadas inúmeras reuniões entre diferentes instituições das cidades fronteiriças para a constituição de um Observatório de Turismo Trinacional. Ação fomentada pelo Poloiguassu, entre outras coisas, com a assinatura de uma carta de intenções com a Organização Mundial do Turismo (OMT) em 2016 , com apoio de Itaipu Binacional, para aproximar as instituições e permitir que a região fronteiriça integre a rede internacional de observatórios de turismo sustentável. Nos anos seguintes uma série de ações, como pesquisas, formações e inúmeras reuniões foram desenvolvidas em conjunto por entidades dos três países, contudo não se alcançou a institucionalização desse observatório até o momento, mas mesmo assim mantém-se a relação de colaboração.

Este é apenas um exemplo de muitos projetos e negociações que o Poloiguassu acompanhou e estimulou nos últimos anos. O Poloiguassu faz parte do Conselho Municipal de Turismo (COMTUR), Agência de Desenvolvimento Turístico da Região Cataratas do Iguaçu e Caminhos ao Lago de Itaipu (ADETUR), possui envolvimento com o Conselho de Desenvolvimento Econômico e Social de Foz do Iguaçu (CODEFOZ) e serve como instituição de apoio técnico do Conselho de Desenvolvimento Trinacional - CODETRI (projeto integrador que reúne os conselhos de desenvolvimento das três cidades da fronteira, Foz do Iguaçu, Ciudad del Este e Puerto Iguazú).

De acordo com Sra. Fernanda (informação verbal, 2020), as relações locais são norteadas pelas necessidades e problemas comuns, mas que carecem de um planejamento de forma estruturada. Então surgem as demandas e as redes trinacionais se mobilizam para solucionar, mas não necessariamente amparadas por uma iniciativa formal, mas sim por diferentes arranjos de cooperação não formais que envolvem iniciativa pública, privada e instituições do terceiro setor.

Nesse sentido, Fernanda aponta o Poloiguassu como pioneiro da articulação para a integração fronteiriça, indicando que as principais fragilidades do instituto são: a falta

\footnotetext{
${ }^{5}$ Matéria sobre a assinatura disponível em: <https://www.itaipu.gov.py/sala-deimprensa/noticia/observatorio-de-turismo-da-regiao-de-foz-sera-integrado-rede-da-omt $>$ Acesso em: 10 de out. de 2020.
} 
de força política e econômica necessária para desenvolver as ações previstas como objetivos. Para ela, isso decorre principalmente porque o Mercosul não se efetivou com relação às facilitações de fronteira. Já sobre as forças do instituto, Fernanda Menciona a independência para trabalhar pelo território o conhecimento técnico e o legado trinacional, como instituição de longa e profunda atuação internacional.

O Poloiguassu realiza e apoia iniciativas de instituições e movimentos orientados para a integração, estruturação e desenvolvimento turístico da Região Trinacional do Iguassu. Mas além disso também executa trabalhos técnicos, como avaliação da qualidade de serviços turísticos, e treinamentos focados no setor turístico. Atividades realizadas ao longo dos anos como prestação de serviço, contratos e convênio com diferentes empresas da região, o que reforça sua atuação técnica e fortalece o seu reconhecimento. Por exemplo, desde 2008 faz avaliação da qualidade dos serviços turísticos do Complexo turístico de Itaipu, aplicando metodologias da ABNT e desenvolvendo metodologias específicas para as necessidades locais, a partir de teorias reconhecidas no mercado.

Por sua atuação integrada na região trinacional, o Poloiguassu, traz grande contribuição no levantamento de dados da região, e na produção científica. Utilizado como fonte primária de coleta de informações por pesquisadores da academia (CURY, 2007; CURY, 2008; DE SOUZA, 2010; BIANCHIN, 2017; PACHECO, 2019; KUERTEN et.al, 2013; PDITS, 2011); reconhecido por sua atuação em espaços de governança turística, gestão integrada do turismo e promoção do turismo sustentável (ROSSI, et al. 2014; TOMIO, et. al. 2014; HENZ, et. al, 2016; CORREA, et. al, 2008; ANJOS, et. al. 2012; MELGAREJO, et. al. 2019; MARIO et. al. 2017); pela participação e atuação em eventos de integração turística (VIEIRA et. al. 2014) e pela realização de projetos voltados à educação e inserção social, como o projeto Trilha Jovem Iguassu (CORREA, et. al, 2008; GOMES, 2018).

Caracterizado como incentivador do turismo regional e do empreendedorismo coletivo, como apontam Rossi et. al. (2014) e Tomio et. al. (2014), ressaltando a participação do Poloiguassu na coordenação do projeto Turismo Sustentável de Base Comunitária no Oeste do Paraná, em parceria com o Educare. Ainda, estimula o envolvimento com a comunidade, através de projetos como o Trilha Jovem Iguassu, indicado por Correa et. al. (2008), como boa prática de Política Pública, e segundo 
Gomes et. al. (2018), o projeto contribui para a dinâmica do mercado de trabalho turístico por meio da qualificação e integração sócio profissional dos jovens com o trade turístico.

Reconhecido como parte da estrutura de gestão do destino de Foz do Iguaçu (FONTANA et. al. 2018), segundo Anjos et. al. (2012), o Polo Iguassu fez parte do processo de reestruturação da Secretaria Municipal de Turismo, em que foi determinada a gestão integrada (caracterizada pela colaboração entre a gestão pública, privada e o terceiro setor). Apontado como uma das principais instituições de turismo do município (MARIO et. al. 2017) e como ator importante no desenvolvimento turístico, Henz et. al. (2016) acentua o instituto como uma das instituições com quem a prefeitura firmou mais convênios em prol da atividade turística até o ano de 2016. Chim-Miki et. al. (2016), ainda demonstra a importância do instituto na rede de cooperação entre os agentes envolvidos no desenvolvimento sustentável do setor turístico na fronteira entre Argentina, Brasil e Paraguai.

Ao longo de sua história, o instituto buscou integrar a região por meio do turismo, realizando projetos voltados à valorização da cultura dos três países, o respeito com os povos e a potencialização dos atrativos turísticos existentes, promovendo um destino turístico trinacional. Hoje, o instituto direciona seu caminho nas áreas de gestão, pesquisa e educação para o turismo, entendendo a importância e a necessidade da geração de conhecimento para o desenvolvimento sustentável.

Atualmente, também está envolvido com o Concurso de Experiências Iguassu, um projeto de cooperação INNOVACT entre a União Europeia (UE) e a Comunidade dos Estados Latino-Americanos e Caribenhos (CELAC) para promover a coesão territorial e o desenvolvimento do turismo sustentável na Tríplice Fronteira Argentina Brasil - Paraguai. Cujo objetivo é incentivar, valorizar e reconhecer as ofertas e atividades turísticas existentes na região trinacional. O concurso é uma iniciativa dos atores locais do Destino Iguaçu, realizada pelo Conselho de Desenvolvimento de Foz do Iguaçu (CODEFOZ), pelo Conselho de Desenvolvimento de Ciudad del Este (CODELESTE) e o pelo Conselho de Desenvolvimento de Econômico, Social e Ambiental de Puerto Iguazú (CODESPI), mas executado pelo Poloiguassu.

O Instituto está ligado, desde 2019, à Rede de Destinos Turísticos Inteligentes da Sociedad Mercantil Estatal para la Gestión de La Innovación y las Tecnologías 
Turísticas, S.A.M.P (SEGITTUR). Esta, busca a inovação, a tecnologia e a promoção do desenvolvimento sustentável do setor turístico através da troca de conhecimento entre seus membros (SEGITTUR, s.d). A participação do Poloiguassu em uma atividade sobre Metodología e ferramentas de gestão de Destinos Turísticos Inteligentes organizada pela SEGITTUR - Sociedad Estatal para la Gestión de la Innovación y las Tecnologías Turísticas, S.A (España), e a AECID - Agencia Española de Cooperación Internacional para el Desarrollo, coloca o instituto em mais uma rede internacional de cooperação e intercâmbio promovida para a integração colaboração entre destinos da América Latina e Caribe.

A experiência adquirida em sua trajetória e o reconhecimento da vocação técnica do instituto pelo trade, parceiros e comunidade o destacam no cenário local, regional, nacional e internacional. Nessa parte do texto mostramos principalmente aspectos que se relacionam e evidenciam a reflexão proposta como objetivo, contudo o instituto e suas diferentes frentes de atuação pode ser estudado e analisado sob inúmeras perspectivas. Por exemplo, a participação em diferentes redes, de diferentes escalas, como regionais, nacionais e internacionais, em cada uma de suas frentes de atuação, permite outras inúmeras análises sobre governança, educação, atuação do terceiro setor, entre outras.

Dessa forma, retrata-se brevemente como se dá a atuação internacional do Poloiguassu à luz da teoria da paradiplomacia, pois a partir dessa concepção foram levantadas e analisadas as atuações que se consideram pertinentes à discussão. Seus objetivos e atuações internacionais ao longo dos anos permitem visualizar a complexidade das relações interinstitucionais fronteiriças e nota-se nesse contexto o potencial articulador do instituto. Sendo que, a princípio teve uma atuação mais de projeção externa e nos últimos anos mais de mediação (a partir da experiência técnica, de captação de recursos e etc), sempre internacional e voltada para o turismo, mostra-se diretamente relacionado ao que se entende como paradiplomacia.

\section{CONSIDERAÇÕES FINAIS}

Como se pôde observar ao longo do trabalho, o Instituto Polo Iguassu surge de uma iniciativa da sociedade civil da Região Trinacional do Iguassu como proposta 
institucional para fortalecimento da integração local principalmente pautada na atividade turística da região. Naquele momento, meados da década de 1990, o contexto sulamericano estava marcado por agenda neoliberal que visava recompor os países avassalados pelas crises dos anos 1980 (crise da dívida) que ainda reverberavam no continente em forma de crises cambiais severas. Neste cenário, o Mercosul despontava como uma esperança para o desenvolvimento do continente de forma integrada, a partir de perspectivas que incluíam mercados pouco explorados anteriormente, como por exemplo o turismo.

Na região trinacional, esse conjunto de fatores, atrelado ao boom do mercado de fronteira liderado pelo comércio de Ciudad del Este (PY), que impulsionou a rede hoteleira do município vizinho, Foz do Iguaçu (BR), bem como a cadeia turística vinculada ao Parque Nacional do Iguaçu - localizado na interseção entre Foz do Iguaçu(BR) e Puerto Iguazu (AR), (BIANCHIN, 2017) propiciou uma mobilização para identificação do potencial turístico da região. E foi a partir da proposta de uma pesquisa que suprisse essa demanda, que surge o Instituto Polo Internacional Iguassu.

Como trabalhado ao longo do estudo - de forma arbitrária, para fins didáticos pode-se dividir a atuação do instituto em dois grandes momentos: um primeiro momento voltado para a representação da região, visando projetá-la internacionalmente e na articulação da localidade com os governos centrais de cada país; e um segundo momento voltado para a gestão de projetos com necessidade de articulação entre os diferentes países a nível local/regional. É interessante ressaltar que em ambos os momentos houve atuação do instituto em ambas as esferas (local/regional e externa), mas com mais preponderância em um ou outra conforme a fase de atuação.

Dessa forma, de modo a responder a pergunta de pesquisa que visou identificar como se dá a atuação internacional do Instituto Poloiguassu na região fronteiriça do Iguaçu, pode-se dizer que atualmente o principal papel do instituto no âmbito internacional é de articulador dos interesses fronteiriços como referência técnica e de gestão de projetos, funcionando como captador e administrador de recursos e tarefas. Exemplos desse papel são: 1) a execução do concurso de experiências do iguassu, produto de um projeto de cooperação INNOVACT entre a União Europeia (UE) e a Comunidade dos Estados Latino-Americanos e Caribenhos (CELAC), realizado pelos Conselhos de Desenvolvimento de Foz do Iguaçu, Ciudad del Este e Puerto Iguazú, 
mas executado pelo Poloiguassu; 2) a gestão do projeto de pesquisa Triangle Cities, com execução técnica do observatório de Meio Ambiente Moema Vizzer, da Universidade Federal da Integração Latino-americana, com recursos e parceria com a universidade de Leads, mas administrados pelo Poloiguassu; e 3) a coparticipação como gestor técnico do observatório municipal de turismo de Foz do Iguaçu, que embora não seja um observatório de abrangência trinacional, produz publicações com levantamentos de dados trinacionais devido a rede de contato estabelecida pelo Instituto Poloiguassu. Contudo, há de se afirmar que inicialmente sua atuação se deu mais no âmbito da articulação política local e projeção da região enquanto bloco. Exemplos disso são:1) a normativa de interesse turístico do Mercosul de 1997; e 2) a associação do instituto à Organização Mundial de Turismo.

Por fim, cabe ainda destacar que, independentemente do momento, o que não foi alterado ao longo dos vinte e quatro (24) anos de atuação do instituto é: 1) seu reconhecimento como referência de informações sobre a região, o que fica explícito tanto pelas pesquisas acadêmicas que o citam, como na fala da Fernanda sobre os convites feitos ao instituto para participar das mais diversas instâncias; e 2) sua participação nas redes de cooperação nacionais e internacionais, sendo elas fronteiriças, transfronteiriças, ou não, estando atualmente vinculado ao CODETRI, ao CODEFOZ, ao COMTUR, a ADETUR, a rede Brasileira de Observatórios de Turismo, a Singetur, aos encontros de localidades fronteiriças vinculadas do Mercosul, ao NAPI Trinacional, dentre outros.

Assim, pode-se dizer que o Instituto Polo Internacional Iguassu é um ator paradiplomático da região trinacional do iguassu tanto a nível local, atuando como articulador técnico na implementação de projetos de interesse comum dos três países, como no âmbito da projeção externa da região participando ativamente como representante da região.

\section{REFERÊNCIAS BIBLIOGRÁFICAS}

AGUIRRE, I. Making sense of paradiplomacy? An intertextual enquiry about a concept in search of a definition. Regional \& Federal Studies. Londres, v. 9, n. 1, p. 158-208. fev. 1999. 
BIANCHIN, Aracelli. O turismo na região trinacional do Iguassu como fator de integração e fragmentação do território da fronteira. 2018. Dissertação de Mestrado. Disponível em: <https://dspace.unila.edu.br/bitstream/handle/123456789/5562/BIANCHIN_A._DISSE RTAO_ICAL_COM_FICHA.pdf?sequence=1\&isAllowed=y $>$. Acesso em: 21 de set. de 2020.

BRASIL. Mercosul. Saiba mais sobre o MERCOSUL. s.d. Disponível em: $<$ http://www.mercosul.gov.br/saiba-mais-sobre-o-mercosul >. Acesso em: 04 de out. de 2020 .

BRASIL. Ministério do Turismo. Entidade brasileira na vice-presidência da OMT. 2012. Disponível em:_<http://www.dadosefatos.turismo.gov.br/ultimas-noticias/1105entidade-brasileira-na-vice-presidencia-da-omt.html>. Acesso em: 04 de out. de 2020.

BRASIL. Plano De Desenvolvimento Integrado Do Turismo Polo Turístico De Foz Do Iguaçu. Ministério do Turismo. 2010. Disponível em: <http://www.turismo.gov.br/sites/default/turismo/DPROD/PDITS/PARANA/PDITS_P OLO_DE_FOZ_DO_IGUACU.pdf>. Acesso em: 22 de set. de 2020.

CHIM-MIKI, Adriana Fumi; BATISTA-CANINO, Rosa María; MEDINA-BRITO, Pino. Coopetición en un destino turístico de frontera entre Argentina, Brasil y Paraguay: el caso Poloiguassu. Semestre Económico, v. 19, n. 40, p. 145-174, 2016.

CONARGO, N. Diplomacy and paradiplomacy in the redefinition of international security: dimensions of conflict and cooperation. Regional \& Federal Studies. Londres, v. 9, n. 1, p. 40-57. fev. 1999.

CORREA, R. A.; GODOY, A. M. G. Políticas públicas e turismo sustentável em Foz do Iguaçu. Revista Paranaense de Desenvolvimento, Curitiba, n.115, p.149-172, jul./dez. 2008.

CURY, Mauro José Ferreira. A região do iguassu: centro estratégico da américa do sul, o turismo e o vencer as fronteiras. 2007 Disponível em: <https://festivaldascataratas.com/wp-content/uploads/2014/01/17.-A-REGI\%C3\%83ODO-IGUASSU-CENTRO-ESTRAT\%C3\%89GICO-DA-AM\%C3\%89RICA-DO-SULO-TURISMO-E-O-VENCER-AS-FRONTEIRAS.pdf>. Acesso em: 21 de set. de 2020.

CURY, Mauro José Ferreira; DINIZ FILHO, Luis Lopes; FRAGA, Nilson César. TERRITORIO TRANSFRONTEIRIÇO DO IGUASSU: as redes e desenvolvimento populacional. 2008 Disponível em: <http://www.observatoriogeograficoamericalatina.org.mx/egal12/Geografiasocioecono mica/Geografiaturistica/45.pdf>. Acesso em: 21 de set. de 2020.

DE FÁTIMA FONTANA, Rosislene; DOS ANJOS, Sara Joana Gadotti; PINTO, Patrícia Susana Lopes Guerrilha Santos. Gestão Turística: Estrutura de Gestão dos Destinos Algarve-Portugal e Foz do Iguaçu-Brasil/Tourist Management. 
Destinations Management Structure in Algarve-Portugal and Foz do Iguaçu-Brazil. ROSA DOS VENTOS-Turismo e Hospitalidade, v. 10, n. 4, 2018.

DE SOUZA, Edson Belo Clemente. Estudo da Região de Fronteira do Brasil com o Paraguai: O turismo nas margens do Lago de Itaipu. 2010. Disponível em: <https://www.ucs.br/ucs/eventos/seminarios semintur/semin tur 6/arquivos/07/Estudo $\% 20 \mathrm{da} \% 20$ Regiao $\% 20 \mathrm{de} \% 20$ Fronteira $\% 20 \mathrm{do} \% 20 \mathrm{Brasi} \% 20 \mathrm{com} \% 20 \mathrm{o} \% 20$ Paraguai $\% 2$ 00\%20turismo\%20nas.pdf>. Acesso em: 21 de set. de 2020.

GOMES, E. C.; VALE, J. A. S. Trilha Jovem Iguassu - Turismo como "porta de entrada" na qualificação profissional de jovens. Universidade Estadual do Oeste do Paraná - UNIOESTE. Foz do Iguaçu. 2019.

KEATING, M. Governing cities and regions: territorial restructuring in a global age. In: SCOTT; A. J. (ed.), Global City-Regions: Trends, Theory, Policy. Oxford: Oxford University Press, p. 371-390. 2001.

KUERTEN, Edinaldo; STOECKL, Karl; NETO, Eduardo Hack. Investigação sobre a qualidade do serviço de transporte no passeio panorâmico da Itaipu Binacional. 2013 Disponível em: <https://festivaldascataratas.com/wp-content/uploads/2014/01/7.INVESTIGA\%C3\%87\%C3\%83O-SOBRE-A-QUALIDADE-DO-SERVI\%C3\%87ODE-TRANSPORTE-NO-PASSEIO-PANOR\%C3\%82MICO-DA-ITAIPUBINACIONAL.pdf>. Acesso em: 19 de set. de 2020.

MARIO, F. A. de. Redes de relacionamentos interorganizacionais no processo de internacionalização em casa: um estudo de caso no Recanto Park Hotel. Universidade Estadual de Maringá. Maringá. 2017

MElgarejo, J. R. Elaboração do Plano Municipal da Mata Atlântica (PMMA) de Foz do Iguaçu: balanço de um processo. International Journal of Environmental Resilience Research and Science (IJERRS). Revista Internacional Resiliência Ambiental Pesquisa e Ciência. ISSN 2675-3456 n1. v1. 2019.

OMT. Membros afiliados. s/d. Disponível em: <https://www.unwto.org/affiliatemembers>. Acesso em: 04 de out. de 2020.

Pacheco, A., \& PACHECO, C. A pesquisa qualitativa como ferramenta de desenvolvimento no turismo: Um estudo de caso do Complexo Turístico da Itaipu 2014 a 2016. Bienal Científica Internacional UNICAN. 2019.

PENHA, W.B; DESIDERÁNETO, A. As regiões de fronteira como laboratório da integração Regional no Mercosul. (org.). Bruna Penha, Walter Antonio Desiderá Neto, Rodrigo Fracalossi de Moraes. In: O Mercosul e as regiões de fronteira. Rio de Janeiro: Ipea, p. 258, 2017.

ROSSI, F.; SCHMIDT, C. M.; ALVES, J. K. D.; DREHER, M. T. Empreendedorismo Coletivo: a Experiência da Região Oeste do Paraná no Contexto do Turismo 
Sustentável. Encontro de Estudos em Empreendedorismo e Gestão de Pequenas Empresas (EGEPE). Goiânia. 2014.

SAKAI, P.; SAKAI, M.; SCHNEIDER, T.; OBERLING, D. F.; OREGGIONI, F.; LÓPEZ, L.; FRANZINI, A. C.; AQUINO, C.; TISCHNER, A.; CABALLERO, N.; PENAGOS, J. Vulnerability Assessment and Adaptation Strategies of the TriangleCity Region. Foz do Iguaçu: the Climate Resilient Cities in Latin America initiative, Cliamate and Development Knowledge Network (CDKN) and Canada's International Development Research Centre (IDRC), p. 238, 2017.

SEGITTUR. Red de Destinos Turísticos Inteligentes en España. s.d. Disponível em: $<$ https://www.segittur.es/destinos-turisticos-inteligentes/proyectos-destinos/red-dti/>.

Acesso em: 10 de out. de 2020.

TOMIO, M.; SCHMIDT, C. M. Governança e ações coletivas no turismo regional: a experiência dos empreendedores da região oeste do Paraná. Turismo - Visão e Ação, vol. 16, núm. 3, setembro-dezembro, 2014, pp. 710-739. Universidade do Vale do Itajaí. Camboriú, Brasil.

VIEIRA, I. K. R.; KNUPP, M. E. C. G.; COSTA, M. R. Gestão integrada e descentralizada: desenvolvimento social e turístico no Destino Iguassu. Fórum Internacional de Turismo. Foz do Iguaçu. 2014

WALTER, A. L. W.; CORRÊA, Ronaldo de Oliveira. Reflexões sobre a perspectiva da identidade em propostas para o artesanato. In: ESOCITE, 2016, Curitiba - PR. XI Jornadas Latino-Americanas de Estudos Sociais da Ciência e da Tecnologia, 2016. 